\title{
Targeting Internal Publics During the 2014 Ebola Outbreak: An Analysis of Kaiser Permanente's Crisis Communication Strategy
}

\author{
Ingrid S. Greene \\ Pepperdine University \\ Malibu, CA \\ Denise P. Ferguson \\ Azusa Pacific University \\ Azusa, CA
}

\begin{abstract}
Issues management in today's quickly changing world can be complex and unpredictable, and in the case of the spread of Ebola, carry lethal implications. Kaiser Permanente (KP) faced a potential internal crisis due to the involvement of medical staff during the spread of the disease in the United States. In addition, KP needed to ensure the safety of the patients the healthcare provider serves. This case study examines how the corporate communications team at KP in Southern California communicated the necessary messages during this crisis in the U.S. in the fall of 2014. The methodology of this case is a textual analysis of the internal corporate communications within Kaiser Permanente during the 2014 Ebola outbreak in the U.S.

Karl Weick's Sense-Making Model and the Human Resources approach are two frameworks used to analyze the KP case study. The organizational leaders at KP followed the three main stages of Weick's model-enactment, selection, and retention [1] — and reflected Theory Y's view of employees as possessing a high capacity for autonomy, responsibility, and innovation (McGegor, 1960).
\end{abstract}

Kaiser Permanente's communication and actions directed towards employees during the Ebola crisis demonstrate how organizations can best communicate with internal audiences during crisis and risk situations and offer best practices.

Keywords - corporate communication, crisis communication, Ebola, internal and external communication

SUGGESTED CITATION: Greene, I. S. \& Ferguson, D. P. (2018). Targeting Internal Publics During the 2014 Ebola Outbreak: An Analysis of Kaiser Permanente's Crisis Communication. Proceedings of the International Crisis and Risk Communication Conference (pp. 30-33). Orlando FL, USA. Nicholson School of Communication. https://doi.org/10.30658/icrcc.2018.9

\section{INTRODUCTION}

This paper provides a case study for how organizations can best communicate with internal audiences during crisis and risk situations. Karl Weick's sense-making model and the Human Resources approach are reviewed and applied to an internal communications case study at Kaiser Permanente during the Ebola virus outbreak in the U.S. in 2014.

While the Ebola virus existed for many years in Africa, in 2014 the Ebola virus no longer existed only on foreign shores. Instead, it had made its way to Dallas, Texas, where one patient died and two nurses were infected [3]. Because health care workers nationwide were now in danger of contracting this serious and potentially lethal disease, all health care providers in the U.S. were required to comply with strict guidelines for hospital procedures. Kaiser Permanente needed to simultaneously communicate to staff that safety was the organization's first priority.

In 2014, Kaiser Permanente (KP) operated 38 hospitals, managed 174,415 employees, and serviced 9.6 million members in the U.S. [4]. With such a large network, it was vital for KP to communicate clearly with both internal and external stakeholders during this crisis. While none of KP's patients would be infected with the Ebola virus, every hospital in the U.S. was encouraged to prepare for an infection. 


\section{THEORY AND CHRONOLOGY REVIEW}

Karl Weick's (1995) sense-making model views organizations as complex learning systems. He posits that leaders need to make sense of equivocal situations via communication. Weick argues that central to organizing is reducing uncertainty through information processing. People "structure the unknown" and try to make sense of the situation. When new pieces of information are received to this framework, it is easier for people to "comprehend, understand, explain, attribute, and predict" [1]. There are three parts to this organizing: enactment, selection, and retention [1]. Enactment occurs when members create environments through their actions and patterns. Selection refers to collective sense-making accomplished through communication. Retention is defined as when successful interpretations are saved for future use. Weick (1995) argued that it is important to always scan for information outside the main environment and collective external expertise.

Encouraging employee participation and dialogue has become necessary in today's quickly changing environment [5]. This approach has evolved from Maslow's hierarchy of needs (physiological, safety, love, self-esteem, and selfactualization), and McGregor's Theory Y Management, in which employees are viewed as possessing a high capacity for autonomy, responsibility, and innovation [6]. Theory Y also includes placing an emphasis on the supportive relationships within work groups and the open communication among them [2].

\section{THE 2014 EBOLA OUTBREAK IN THE U.S.}

The first outbreak of Ebola occurred in Zaire in 1976 with 280 deaths. Up to 4000 cases are found in certain areas within these African countries. In July 2015, the total number of cases globally was more than 27,000, and the total number of deaths was over 11,000, [7]. When this deadly disease arrived on U.S. shores it created concern, fear, and mistrust about the readiness of the nation's health care system to cope with the disease [4].

The CDC very quickly updated the guidelines for treating an Ebola victim. In September 2014, a Liberian native lied on his immigration form about his exposure to the virus when travelling from Africa to the U.S. Thomas Eric Duncan was admitted to Texas Presbyterian Health Hospital in Dallas with symptoms of a cold. Three days after being sent home he was diagnosed with the first case of Ebola in the U.S. and died on October 8, 2014 [3]. Within a week, two nurses who were caring with Duncan were diagnosed with Ebola.

Fortunately, neither of the nurses died from the virus. However, the Ebola scare galvanized nurses across the U.S. to protest against their employers and question healthcare protocol. Kaiser Permanente nurses felt that their employer was not taking adequate safety precautions to protect them against Ebola. The unions acted quickly to protect their members through strikes, protests, and negotiation. Kaiser Permanente faced an urgent need to communicate clearly and effectively with the nurses, doctors, and all hospital staff during this crisis situation that exposed health care staff and members to serious risks. Even the updated response from the CDC did little to produce confidence in the ability of the nation's healthcare system to respond appropriately [4].

\section{METHODS OR PROCEDURES}

Textual analysis was conducted on Kaiser Permanente internal communications. Access to KP internal documents was given by the Director of Public Affairs and Brand Management at Kaiser Permanente and her team. They sent the authors over 30 documents, including samples of newsletters, company-wide emails, training documents, and internal corporate communication tools. The documents were received during November of 2015 and the documents represent a period between October 2014 and January 2015.

\section{RESULTS}

Karl Weick's model posits that organizations are highly complex and, therefore, leaders need to make sense of ambiguous situations via communication [1]. Weick's (1995) research shows that the cognitive processes individuals use in organizations involve trial and error, chance, superstitious learning, and retrospective sense-making through the three main stages of enactment, selection, and retention.

Immediately after the U.S. Ebola outbreak, the organizational communications team at KP began to collect information from the Center for Disease Control (CDC) and to implement the CDC's requests, otherwise known as enactment. Enactment involves an organization constructing a new reality through leaders' authoritative acts [1]. Trial and error was clear when KP decided to implement the first set of instructions from the CDC. The error in this decision and communication was that the protocol was not strict enough to protect the health care staff. Materials, or information, are seized or dismissed in the selection process [1]. Selection began when the CDC protocols were not accepted, the health care staff began to demand greater protection, and new guidelines were requested from the national authorities. Seeing that the framework had been set during the enactment phase, the selection stage of the sense-making model could be initiated. Collective sense-making began via communication between the organization, the CDC, and the staff. The organizational communication staff at KP now had a solid foundation, or frame of reference, from which to process the crisis. Retention reinforces the selections and options, and includes remembering developed interpretations for later use 
[1]. The organizational communication team often reviewed their previous work and then improved upon previous actions. KP used the triage approach to crisis communication [4]. This prioritizes issues that need to be addressed immediately, issues that need to be addressed later, and issues that can wait a longer period of time [1]. The next section discusses the role and actions of KP leaders, applying the Human Resources approach. In addition, the company website was analysed.

The Human Resources approach posits that employees are viewed as possessing a high capacity for autonomy, responsibility, and innovation, according to Macgregor's Theory Y management theory. During an interview with the Managing Director of Integrated Brand Communications at KP, it was expressed that KP leaders believed that if staff members were given the appropriate and safe guidelines, they would feel more secure about working under the Ebola conditions. KP leaders followed up with multiple trainings, literature, and information for staff to ensure that everyone was well-informed. From admittance staff to nurses to doctors, all levels of guidelines and instructions were supplied to KP health care professionals.

By communicating clearly to the physicians and employees, KP leaders believed that both staff members and patients would remain calm throughout the crisis. Theory Y also includes placing an emphasis on the supportive relationships within work groups and the open communication among them. For example, KP published a flyer with the names, positions, and photos of the 23 members of the Ebola Preparedness Team for distribution to all employees. Positions included the Executive Director, Ebola Manager, and Manager of Human Resources and Training. By creating transparency and access to senior level management, it supported the Theory Y posit of open communication. KP also provided safety suits, a procedure for working with potential Ebola patients, and assigning specific hospitals where Ebola patients would be treated with their families.

After the strategies were set, the corporate communications team put together tactics for rollout. These are some of the tactics Kaiser Permanente concluded to be successful [4]:

- $\quad$ Established the Ebola Work Group (EWG), which produced daily updates and recorded daily meetings

- Minimized duplicate mailing of information and quickly responded to key issues

- $\quad$ Created an easy, one-stop access to information on company website

- Ensured all physicians, laboratory scientists, and technicians understood the need to read Infection Connection and/or go to the Infectious Disease website for the latest clinical updates

- Used physician chiefs to cascade information to physicians

- Implemented a weekly update by the Area Medical Director based on news from the Ebola Oversight Group

- Created an e-newsletter, entitled, "Care \& Safety: Ebola Update,” to focus on education and awareness building among medical center-based employees (nurses, EVS and Waste Management, Procurement, Laboratories, KP On Call, Corona Call Center, medical center Advice and Appointments and Member Services, KFH/HP and SCPMG Communications, KP HealthConnect, and Labor)

- Used internal news channels: IKP@SCAL, KP Matters, Medical Center Intranet Sites, Medical Center newsletters

\section{DISCUSSION}

The Ebola outbreak created significant perceptions of risk and fear among health care providers as well as the general public. Kaiser Permanente leaders quickly made it a top priority to ensure that staff members were kept up-to-date and informed during the Ebola crisis. Initially, the triage strategy allowed the corporate communications team to prioritize which internal and external constituents needed answers first. Next, the KP communications team outlined the tactics for the organization's communication strategy and assigned key responsible parties for each step in the process. Not only did this ensure that messages were distributed, but it also aligned an appropriate staff member to communicate the appropriate message

Over the next few weeks of implementation, the KP communications team involved many senior managers in the delivery of key trainings, guidelines, and general messages. This was important in ensuring that the recipients of the messages felt they could trust and rely on the instructions. In addition, the communications team and key directors of the Ebola program made themselves available for questions. Useful communication tools such as press releases and featured stories were used on the corporate website to communicate with the media, KP members, and the general public about the status of the issue.

One of the best ways to evaluate success after a crisis from a communication perspective is to get the reaction from the audience that was affected. Coombs (2015) also recommends collecting reactions from stakeholders affected by the crisis that indicate their assessment of the crisis management performance. Since the nursing staff made up a majority of the key stakeholders, their evaluation of the crisis management was most valuable for the KP communications team. In January 2015, the nurses published a message that the KP communications team believes expresses the success of the company's management of the Ebola crisis. On the front cover of an internal KP newspaper, a picture of a group of smiling nurses and the headline proclaim "We're Ready" [4]. This photo was published only three months after nurses 
had threatened to strike, following a large demonstration in November of 2014 by nurses of competitive hospitals.

\section{CONCLUSION}

By 2014, American health care providers were required to be prepared for the Ebola virus. After one patient died in Dallas, TX, health care staff was in danger of contracting such a serious disease. For all providers, it became necessary to communicate to their staff that safety was the organization's first priority. With such a large network, it was vital for KP to communicate clearly during this crisis.

The CDC and the medical workers realized that the guidelines for working with infected patients were inadequate. Very quickly, nurses and doctors became fearful for their safety, and were expecting answers. Fortunately, the crisis communications team at KP quickly created a strategy developed with a triage approach that enabled them to prioritize who needed answers first. As this case has illustrated, there were numerous regular messages were conveyed across multiple communication platforms over a period of a few weeks to educate staff members as well as to communicate with external stakeholders, which allowed Kaiser Permanente to successfully survive a potential internal crisis that could have disrupted health care services to Ebola victims.

Karl Weick's Sense-Making Model and the Human Resources approach are two frameworks used to analyze the KP case study. The organizational leaders at KP followed the three main stages of Weick's model: enactment, selection, and retention. Enactment engages an external environment and the initial, but limited, protocol provided by the CDC allowed for KP to move through this stage of the model. Initial decisions were made and the issue environment was created. The selection phase includes collective sense making via communication, and the KP healthcare staff provided the dialogue for management. The retention phase was implemented during this case after KP was successful in reinforcing the selections and options for later use. This communication plan—entitled the LAMC (Los Angeles Medical Center) Ebola Preparedness Communications_ - outlines the strategies and tactics used during the Ebola outbreak and which could be used as reference in other similar crises.

The Human Resources approach analysis focused primarily on applying McGregor's Theory Y, which posits that employees are viewed as possessing a high capacity for autonomy, responsibility, and innovation [2]. Theory Y also places an emphasis on the supportive relationships within work groups and the open communication among them.

\section{Author Biography}

Ingrid S. Greene has an MBA from The Thunderbird School of International Management and a Master of Arts from Pepperdine University. Her email address is ingrid.s.greene@gmail.com.

Denise P. Ferguson has a PhD from Purdue University and is currently Associate Dean for Graduate Programs and Research and Professor of Communication for the College of Liberal Arts and Sciences (CLAS) at Azusa Pacific University. Her email address is dferguson@apu.edu.

\section{REFERENCES}

[1] Weick, K. (1995). Sensemaking in Organisations. London: Sage.

[2] McGregor, D. (1960). The Human Side of Enterprise, New York, McGrawHill.

[3] Botelho, G. (2014, October 14). U.S. Ebola patient: The travels and health travails of Thomas Eric Duncan. Retrieved from http://www.cnn.com/2014/10/01/health/us-ebola-patient/

[4] Owens, R. (2015a). Communicating about the Ebola virus to strengthen trust and confidence. Pasadena: Kaiser Permanente. Retrieved by author by email.

[5] Becker, B., \& Gerhart, B. (1996). The Impact of Human Resource Management on Organizational Performance: Progress and Prospects. The Academy of Management Journal, 39(4), 779-801. Retrieved from http://www.jstor.org/stable/256712

[6] Eisenberg, E., Goodall, H.L., and Tretheway, A. (2014). Organizational Communication: Balancing Creativity and Constraint. NewYork: St. Martin's Press.

[7] Center For Disease Control. (2012). Crisis Emergency Risk Communication. Retrieved from http://emergency.cdc.gov/cerc/resources/pdf/cerc_2012edition.pdf.

[8] Chong, M. A Crisis of Epidemic Proportions: What Communication Lessons Can Practitioners Learn from the Singapore Sars Crisis?. (2006). Public Relations Quarterly. 51, (1), 6-11. http://ink.library.smu.edu.sg/lkcsb_research/248

[9] Neal, H. (1962). Better communication for better health. New York: Columbia University Press.

[10] Coombs, T. W. (2015). Ongoing Crisis Communication: Planning, Managing, and Responding. (p. 165). Thousand Oaks: Sage. 